\title{
Comprehensive CFTR gene analysis of the French cystic fibrosis screened newborn cohort: implications for diagnosis, genetic counseling, and mutation-specific therapy
}

\author{
Marie Pierre Audrézet, $\mathrm{PhD}^{1,2}$, Anne Munck, $\mathrm{MD}^{3,4}$, Virginie Scotet, $\mathrm{PhD}{ }^{2,5,6}$, \\ Mireille Claustres, MD, $\mathrm{PhD}^{7-9}$, Michel Roussey, $\mathrm{MD}^{3,10}$, Dominique Delmas, $\mathrm{MA}^{3}$, \\ Claude Férec, MD, PhD ${ }^{1,2,5,6}$ and Marie Desgeorges, PharmD ${ }^{7-9}$
}

\begin{abstract}
Purpose: Newborn screening (NBS) for cystic fibrosis (CF) was implemented throughout France in 2002. It involves a four-tiered procedure: immunoreactive trypsin (IRT)/DNA/IRT/sweat test was implemented throughout France in 2002. The aim of this study was to assess the performance of molecular CFTR gene analysis from the French NBS cohort, to evaluate CF incidence, mutation detection rate, and allelic heterogeneity.
\end{abstract}

Methods: During the 8-year period, 5,947,148 newborns were screened for cystic fibrosis. The data were collected by the Association Française pour le Dépistage et la Prévention des Handicaps de l'Enfant. The mutations identified were classified into four groups based on their potential for causing disease, and a diagnostic algorithm was proposed.

Results: Combining the genetic and sweat test results, 1,160 neonates were diagnosed as having cystic fibrosis. The corresponding incidence, including both the meconium ileus (MI) and false-negative cases, was calculated at 1 in 4,726 live births. The CF30 kit, completed with a comprehensive CFTR gene analysis, provides an excellent detection rate of $99.77 \%$ for the mutated alleles, enabling the identification of a complete genotype in $99.55 \%$ of affected neonates. With more than 200 different mutations characterized, we confirmed the French allelic heterogeneity.

Conclusion: The very good sensitivity, specificity, and positive predictive value obtained suggest that the four-tiered IRT/DNA/IRT/ sweat test procedure may provide an effective strategy for newborn screening for cystic fibrosis.

Genet Med advance online publication 14 August 2014

Key Words: allelic heterogeneity; cystic fibrosis; immunoreactive trypsin; incidence; newborn screening

\section{INTRODUCTION}

Cystic fibrosis (CF; OMIM 219700), a multisystem disease in which lung involvement is the major cause of morbidity and mortality worldwide, remains the most common life-limiting autosomal recessive disease in Caucasian populations. It results from mutations in the cystic fibrosis transmembrane conductance regulator (CFTR; OMIM 602421) gene and is characterized by exocrine secretion abnormalities, chronic pulmonary deterioration with obstructions and infections, pancreatic insufficiency, hepatobiliary manifestations, male infertility, and elevated sweat chloride concentrations.

More than 1,900 sequence variations (disease and nondisease causing mutations) have been reported in the CFTR gene (Cystic Fibrosis Genetic Analysis Consortium, http:// www.genet.sickkids.on.ca/CFTR/app). It is difficult to predict the ultimate clinical outcomes of particular CFTR mutations because gene modifiers and environmental factors combine in determining the phenotypic severity of lung disease. ${ }^{1}$
Diagnosis of CF, based on clinical symptoms, is often delayed because of the lack of specificity of the wide variety of presenting symptoms. Newborn screening (NBS) therefore has been advocated to reduce delays in diagnosis and facilitate early preventive care with respiratory and nutritional treatment. NBS has been reported to be beneficial, even in the context of modern treatments. ${ }^{2-6}$ Based on previous French regional pilot studies ${ }^{7,8}$ and international studies, as well as the demonstration that the immunoreactive trypsin (IRT) assay combined with molecular analysis for CF mutations is a feasible method for routine screening, ${ }^{9}$ the regulatory agencies (the national health insurance funding agency (Caisse Nationale d'Assurance Maladie des Travailleurs Salariés) and the Ministry of Health) mandated the Association Française pour le Dépistage et la Prévention des Handicaps de l'Enfant to organize systematic CF NBS in France and La Réunion Island under the same framework as other NBS tests. The four-tiered screening protocol involves an IRT/DNA/ fail-safe IRT/sweat test (ST) procedure.

\footnotetext{
${ }^{1}$ Laboratoire de Génétique Moléculaire et d'Histocompatibilité, CHU de Brest, Brest, France; ${ }^{2}$ INSERM U1078, Brest, France; ${ }^{3}$ Association Française pour le Dépistage et la Prévention des Handicaps de l'Enfant, Paris, France; ${ }^{4}$ CRCM-Service de Gastro-Entérologie-Mucoviscidose et Nutrition Pédiatriques, Université Paris 7, Hôpital Robert Debré, Paris, France; ${ }^{5}$ Université de Bretagne Occidentale, Brest, France; ${ }^{6}$ Etablissement Français du Sang-Bretagne, Brest, France; ${ }^{7}$ Laboratoire de Génétique Moléculaire, IURC, CHU de Montpellier, Montpellier, France; ${ }^{8}$ INSERM U827, Laboratoire de Génétique des Maladies Rares, Montpellier, France; ${ }^{9}$ Université Montpellier 1, UFR de Médecine, Montpellier, France;

${ }^{10} \mathrm{CRCM}$-Département de Médecine de l’Enfant et de l’Adolescent, CHU de Rennes-Hôpital Sud, Rennes, France. Correspondence: Marie Pierre Audrézet

(marie-pierre.audrezet@chu-brest.fr)
} 
The present study reports the performance of comprehensive molecular CFTR gene analysis in the French CF-NBS cohort using data collected during an 8-year period from 1 January 2002 to 31 December 2009 and evaluates the CF incidence, the mutation detection rate, and the allelic heterogeneity in France.

\section{Patients}

\section{MATERIALS AND METHODS}

France is divided into 22 administrative regions, each of them having its screening laboratory linked to a regional association. The systematic region-by-region national NBS program was implemented from January 2002 to early 2003, and data were collected from 1 January 2002 to 31 December 2009.

Dried blood samples were obtained at 3 days of age for almost all neonates born during the studied period ( $n=5,947,148)$. To fulfill requirements of French bioethical legislation for genetic analysis, written informed consent for DNA testing was obtained from parents and recorded on the back of the filter paper. ${ }^{10}$ All data were rendered anonymous, and processing was declared to the Data Protection Commission (Commission Nationale Informatique et Libertés) under the number 1150693.

\section{Screening strategy}

During the first month of the program, the protocol flowchart was modified twice. ${ }^{11}$ First, because the percentage of neonates with an IRT at day 3 was above the target cutoff of $0.5 \%$ (i.e., $0.82 \%$ ), the day 3 IRT cutoff was raised from 60 to $65 \mathrm{ng} / \mathrm{ml}$. Second, it was decided to repeat IRT at day 21 for infants with a day 3 IRT $\geq 100 \mathrm{ng} / \mathrm{ml}$ and to refer neonates with a day 21 IRT $\geq 40 \mathrm{ng} / \mathrm{ml}$ to a CF center.

The following four-tiered screening strategy was used:

1. IRT measurement at 3 days of age using a radiolabeled immunoassay (RIA-gnost trypsin neonatal kit, CISBIO International, Bagnols/Cèze, France) or an enzymelinked immunospecific assay (Delfia Neonatal IRT Kit, PerkinElmer, Wallac Oy, Finland) in one of the 22 regional screening laboratories.

2. Investigation of the 30 most common mutations responsible for CF (Table 1) using a CF30 Kit (Elucigene CF30, Gen-Probe, San Diego, CA) when the IRT value was above the 99.5 th percentile $(65 \mathrm{ng} / \mathrm{ml})$. This "French" kit was developed to ensure $\geq 80 \%$ mutation detection in all regions of France, based on a previous national study in symptomatic CF patients, ${ }^{12}$ and was validated by a working group mandated by the Association Française pour le Dépistage et la Prévention des Handicaps de l'Enfant.

3. IRT retest at 21 days of age if no mutation was identified in hypertrypsinogenemic neonates with day 3 IRT above the 99.9 th percentile $(100 \mathrm{ng} / \mathrm{ml})$, or if written consent for DNA testing was not obtained.

4. ST analysis in a CF care center to determine CF or nonCF status when one or two mutations were identified or, in the absence of mutation, when day 21 IRT exceeded $40 \mathrm{ng} / \mathrm{ml}$ (99.5th percentile). According to published guidelines, ${ }^{13-16}$ the reference ranges of neonate sweat chloride levels are: $<30 \mathrm{mmol} / \mathrm{l}^{-1}$, negative; $30-59 \mathrm{mmol} /$ $\mathrm{l}^{-1}$, borderline; and $\geq 60 \mathrm{mmol} / \mathrm{l}^{-1}$, positive.

\section{Genetic laboratories}

French molecular genetics laboratories are typically organized into two levels:

1. Level 1: Nine laboratories (located in Brest, Caen, Lille, Lyon, Reims, Montpellier, Paris (Trousseau Hospital and Necker Hospital), and Toulouse) were associated with the NBS program; rapid standardized tests were performed to identify the 30 most common mutations in all neonates with positive day 3 IRT.

2. Level 2: French CF network. In case of hypertrypsinemia with one or no mutations on the CF30 test and a borderline or positive ST, new blood samples underwent complementary analysis in one of the four reference laboratories (Brest, Créteil, Montpellier, Paris-Cochin) or six specialized laboratories (Angers, Bordeaux, Lille, Lyon, Poitiers, Toulouse) of the French CF network. As a second-line diagnostic test for neonates in whom $\mathrm{CF}$ or CFTR-related disorders (CFTR-RDs) have already been diagnosed by ST and clinical assessment, these laboratories offer comprehensive CFTR gene analysis by scanning methods such as denaturing gradient gel electrophoresis, ${ }^{17}$ denaturing high-performance liquid chromatography, ${ }^{18}$ or high-resolution melting ${ }^{19}$ on all 27 exons and their intron boundaries to identify point mutations or small insertions/deletions, followed by sequencing of polymerase chain reaction products displaying abnormal patterns, and semiquantitative fluorescent multiplex polymerase chain reaction ${ }^{20}$ or CFTR Vs03 MLPA assay (MRC-Holland; Amsterdam, The Netherlands) to detect large rearrangements.

\section{Referral to a CF center, ST, and clinical presentation}

In parallel to the CF-NBS program, clinical CF centers (Centres de Ressources et de Compétences de la Mucoviscidose [CRCMs]) have been set up for multidisciplinary management and follow-up. The missions of the CRCMs are, among others, to confirm and to explain the diagnosis of $\mathrm{CF}$ and to ensure follow-up for all screened CF patients. ${ }^{11}$

The ST, which is the gold standard to confirm or rule out a diagnosis of $\mathrm{CF}$, particularly when mutations of uncertain clinical relevance are identified, was performed at the first CRCM consultation, in line with French guidelines. ${ }^{21}$ Falsenegative results were monitored by the CRCM using an annual questionnaire.

\section{Program surveillance and data collection}

The data were centralized by the Association Française pour le Dépistage et la Prévention des Handicaps de l'Enfant. From screening laboratories and regional associations, the monthly distribution of IRT values and the number of molecular biology 
Table 1 Allelic frequencies of CF30-kit mutations, identified in neonates with CF, and correspondence between traditional mutation nomenclature and that on the Human Genome Variation Society website

\begin{tabular}{|c|c|c|c|c|c|}
\hline Frequency (F) \% & Mutation & Legacy mutation nomenclature & $\begin{array}{l}\text { Number of } \\
\text { alleles/2,320 }\end{array}$ & $\begin{array}{c}\% \text { of } \\
\text { alleles } / 2,320\end{array}$ & Cumulative \% \\
\hline \multirow{2}{*}{$\geq 5$} & p.Gly542* & G542X & 113 & 3.19 & 10.51 \\
\hline & c. $1585-1 \mathrm{G}>\mathrm{A}$ & $1717-1 \mathrm{G}>\mathrm{A}$ & 48 & 1.47 & \\
\hline \multirow[t]{7}{*}{$1.00 \geq F \geq 4.99$} & c. $2657+5 G>A$ & $2789+5 G>A$ & 37 & 1.42 & \\
\hline & p.Arg553* & R553X & 36 & 1.29 & \\
\hline & p.Tyr122* & Y122X & 26 & 0.97 & 6.86 \\
\hline & c. $2988+1 G>A$ & $3120+1 G>A$ & 22 & 0.82 & \\
\hline & c. $579+1 G>T$ & $711+1 \mathrm{G}>\mathrm{T}$ & 18 & 0.67 & \\
\hline & p.lle507del & I507del & 17 & 0.63 & \\
\hline & c. $3140-26 A>G$ & $3272-26 A>G$ & 16 & 0.59 & \\
\hline \multirow{7}{*}{$0.40 \geq F \geq 0.99$} & c.2051_2052delinsG & $2183 A A>G$ & 12 & 0.45 & \\
\hline & c.3528delC & 3659delC & 11 & 0.41 & \\
\hline & c. $1680-886 A>G$ & $1811+1.6 \mathrm{kbA}>\mathrm{G}$ & 9 & 0.39 & \\
\hline & p.Gly85Glu & G85E & 8 & 0.34 & 3.06 \\
\hline & p.Ser1251Asn & $\mathrm{S} 1251 \mathrm{~N}$ & 7 & 0.30 & \\
\hline & p.Arg334Trp & R334W & 7 & 0.30 & \\
\hline & p.Arg117His & $\mathrm{R} 117 \mathrm{H}$ & 7 & 0.30 & \\
\hline \multirow[t]{3}{*}{$0.1 \geq F \geq 0.39$} & p.Trp846* & W846X & 6 & 0.26 & \\
\hline & c. $489+1 \mathrm{G}>\mathrm{T}$ & $621+1 G>T$ & 6 & 0.26 & \\
\hline & c.948delT & 1078delT & 5 & 0.22 & \\
\hline
\end{tabular}

Mutations are clustered into four groups of frequency intervals $(>5 \%, 1-4.99 \%, 0.99-0.4 \%$, and $<0.4 \%)$. The total number of alleles in the 1,160 neonates classified as having CF was 2,320.

CF, cystic fibrosis.

tests were collected. The following items for referred infants were collected from the CF centers: IRT results, genotype, ST values, and initial clinical symptoms. During the period of the present study, data were analyzed every 3 months by the technical committee of the Association Française pour le Dépistage et la Prévention des Handicaps de l'Enfant in order to verify the performance of the kit and to monitor the percentage of positive screens.

\section{Nomenclature}

The international nomenclature recommended by the Human Genome Variation Society (http://www.hgvs.org/mutnomen/) was followed. For convenience, the previous legacy mutation nomenclature initially used by the International Consortium Mutation Database (http://www.genet.sickkids.on.ca/CFTR/app), which follows CFTR gene numbering (GenBank NM_00492.3 with the A of the ATG translation start codon numbered +133), is also shown in parentheses at the first occurrence in the text.

\section{Classification of mutations and genotypes}

In CF, as in many other diseases, the term "mutation" is commonly used to indicate "a disease-causing change," and the term "polymorphism" is used to indicate "a non-disease causing change" or "a change found at a frequency of $1 \%$ or higher in the population." To avoid repetition and to prevent any confusion, because the molecular abnormalities described in this article cannot all be classified as "CF-causing" mutations, we use the terms "variations," "variants," or "molecular defects" to designate the different nucleotide changes identified.

Mutations. Because only a limited number of functional studies have assessed the pathogenicity of variants, mutations have been classified in previous studies according to their diseasecausing potential. ${ }^{16,22,23}$ Based on the recommendations and data from these studies (UMD-CFTR-France), ${ }^{24}$ variants were classified into four groups: A, CF-causing; B, associated with CFTR-RDs; C, no clinical consequences; and $\mathrm{D}$, unknown or 
uncertain clinical relevance. Some molecular defects associated with a wide phenotypic spectrum might belong to either group A or group B and therefore were classified as group A/B.

Genotypes. According to the classification of the mutations or variants (A, B, C, or D) and the ST values, neonates were classified according to the diagnostic algorithm shown in Figure $\mathbf{1 b}$. Neonates carrying a homozygous AA genotype, a compound heterozygous genotype for $A$ and $A / B$ mutation and with positive ST were classified as CF. The CF status of other neonates $(\mathrm{AB}$, $\mathrm{AC}, \mathrm{AD}, \mathrm{A} /-$ ) was based on ST values; in cases of positive ST, the children were classified as having CF; if the ST was negative or borderline, they were classified as having CFTR-RDs; and when no ST results were available, neonates remained unclassified.

\section{Statistical analysis}

Statistical analysis was conducted using an Excel spreadsheet and EpiInfo software (version 6.04). The incidence with its 95\% confidence interval $(95 \% \mathrm{CI})$ was determined for the whole study period. The validity of the screening protocol was assessed by estimating the sensitivity, specificity, and positive predictive value and negative predictive value parameters. Mutation frequencies were compared using the $\chi^{2}$ test. All tests were twosided, and a $P$ value less than $5 \%$ was considered significant.

\section{Overall data of the NBS program \\ RESULTS}

Dried blood samples were obtained at 3 days of age for almost all neonates (less than $0.01 \%$ of parents refused NBS). Between 2002 and 31 December 2009, 34,845 of the 5,947,148 screened newborns $(0.58 \%)$ had a day 3 IRT test value above the cutoff level and underwent CFTR DNA 30-mutation analysis (Figure 1a). Of these, 1,005 and 2,830 , respectively, had two or one mutation; 16,201 neonates were recalled; and $92.72 \%(n=15,023)$ had a repeat IRT test at day 21 . A total of 5,492 neonates were referred to a CF center for ST.

Finally, according to IRT findings, DNA analysis and ST values, or clinical symptoms, the number of neonates screened positive for CF was 1,347 .

Three hundred forty-two of these had one or no mutation detected by the CF30 panel, and samples from 341 (one family refused complementary analysis) underwent comprehensive gene analysis in 1 of the 10 specialized laboratories. As a result, 198 other mutations or variations were identified in an additional 335 neonates. After comprehensive gene analysis, only seven infants had one unidentified allele.

\section{Mutations and molecular defects}

According to their predicted clinical consequences, the mutations were clustered into four groups. CF-causing mutations (group A) comprised 142 mutations responsible for classic CF. CFTR-related disorder-associated variants (group B) comprised 13 alterations, including one splice variant and 12 missense mutations. p.Arg117His (R117H) was the second most frequent alteration in the cohort as a whole ( $7.8 \%$ of patients; $n$
= 105). The phenotypic variability of this mutation was mostly attributable to the presence of a polypyrimidine variant with seven (T7) or five (T5) thymidines in the intron 9 (IVS8) acceptor splice site, affecting the splicing efficiency of exon 9.25,26 T5 causes a more severe phenotype, and T7 is considered a neutral mutation. In our population, all individuals carried T7.

Some molecular defects that could belong to either the CF-causing group or the CFTR-related disorders group (group $\mathrm{A} / \mathrm{B}$ ) were reported in patients presenting a broad spectrum of phenotypes from classic CF to mild monosymptomatic presentations. ${ }^{16}$ These are four missense mutations (p.Leu206Trp (L206W), p.Arg347His (R347H), p.Asp1152His (D1152H), and p.Ser945Leu (S945L)) and three splice mutations (c.2657+5G $>A$ $(2789+5 \mathrm{G}>\mathrm{A}), \mathrm{c} .3718-2477 \mathrm{C}>\mathrm{T}(3849+10 \mathrm{kbC}>\mathrm{T})$, and c.121034TG(13);1210-12T(5) (TG13T5)).

Sixty-four other variants of unknown or uncertain clinical relevance (group D) were identified in 3 homozygous and 81 compound heterozygous patients. For these variants, the pathogenicity could not be predicted a priori because these mutations were rare or were reported here for the first time.

Based solely on the CF30 results, at least 1 mutant allele was identified in 1,317 (97.77\%) neonates, 1,005 of whom (74.61\%) had a complete genotype. A total of 30 neonates had no identified mutation; these and the 312 with one mutant allele underwent comprehensive gene analysis in 1 of the 10 level 2 laboratories, resulting in identification of a complete genotype in 1,340 of the $1,347(99.48 \%)$ neonates.

\section{Classification of neonates and incidence}

Combining the results of exhaustive genetic testing and STs, neonates were classified according to the diagnostic algorithm as shown in Figure 1b: 1,160 neonates carrying two CF-causing mutations and/or who were ST-positive were diagnosed with CF; 184 with subthreshold STs and carrying mutations associated with CFTR-related disorders or mutations of unknown or uncertain clinical relevance were classified as having CFTR-RDs; 3 carrying variants of unknown or uncertain clinical relevance without available ST values could not be classified.

Finally, the 4,234 children with a negative ST and either one CFTR gene mutation or no mutation but a persistent hypertrypsinemia at day 21 represent the false-positive results.

The numbers of screened neonates and cases detected, incidence, sensitivity, specificity, and positive and negative predictive values for the screening protocol overall and for CF patients are given in Table 2 .

The median age at diagnosis for CF children, excluding the MI cases and the neonates born after prenatal diagnosis, was 34 days (range, 6-238; interquartile range, 28-44). It was significantly higher for children who were carriers of one or no mutations of the CF30 kit (43 (interquartile range, 32-61) and 44 (interquartile range, 37-66) days, respectively; $P<0.0001$ ).

A total of 577 CF patients (49.74\%) were homozygous for mutations identified by the CF30 kit, including p.Phe508del $(n=552,47.58 \%)$, p.Gly542* $(n=5,0.43 \%)$, and p.Asn1303Lys 


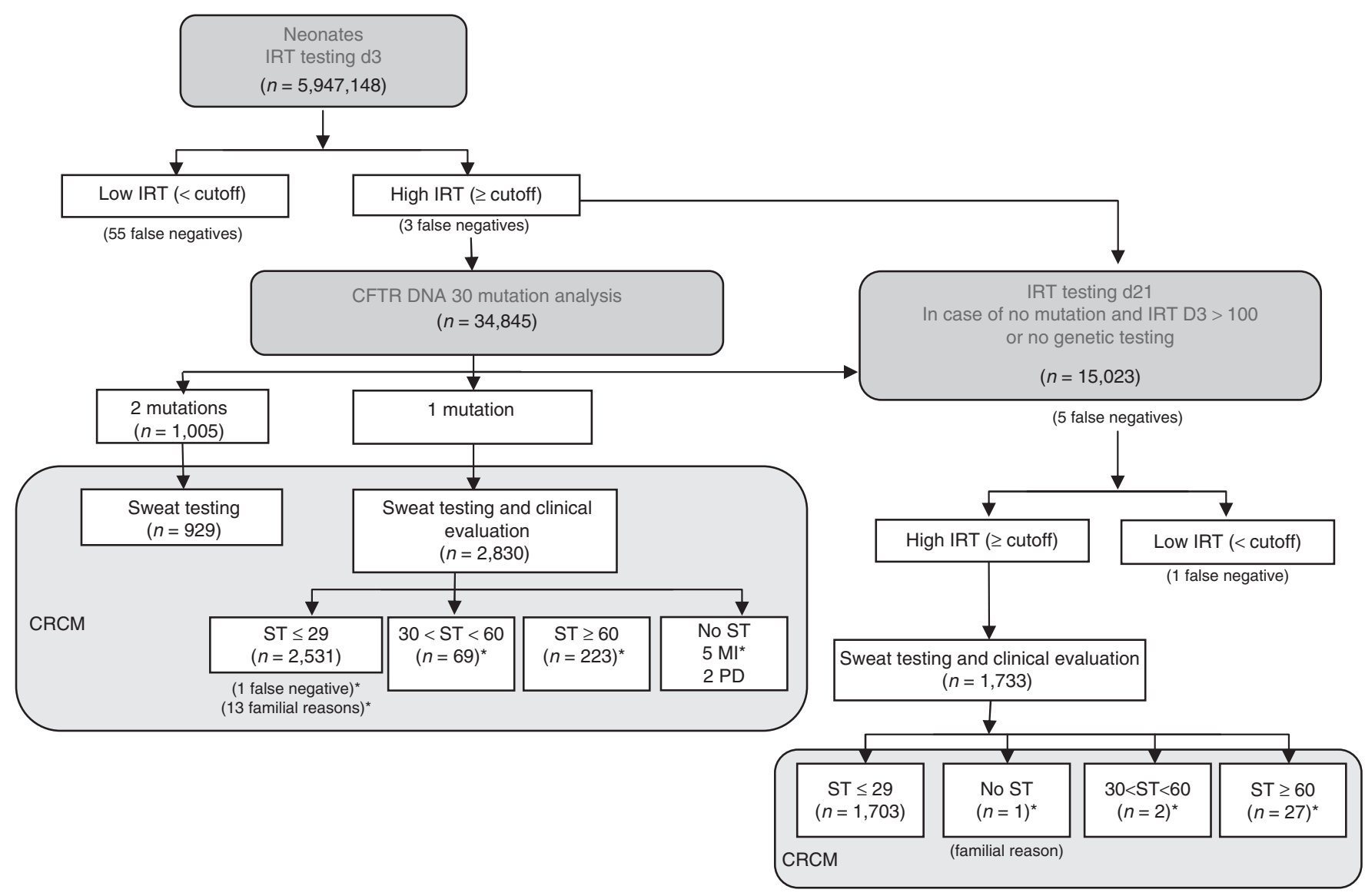

b Decision algorithm for classification of the neonates

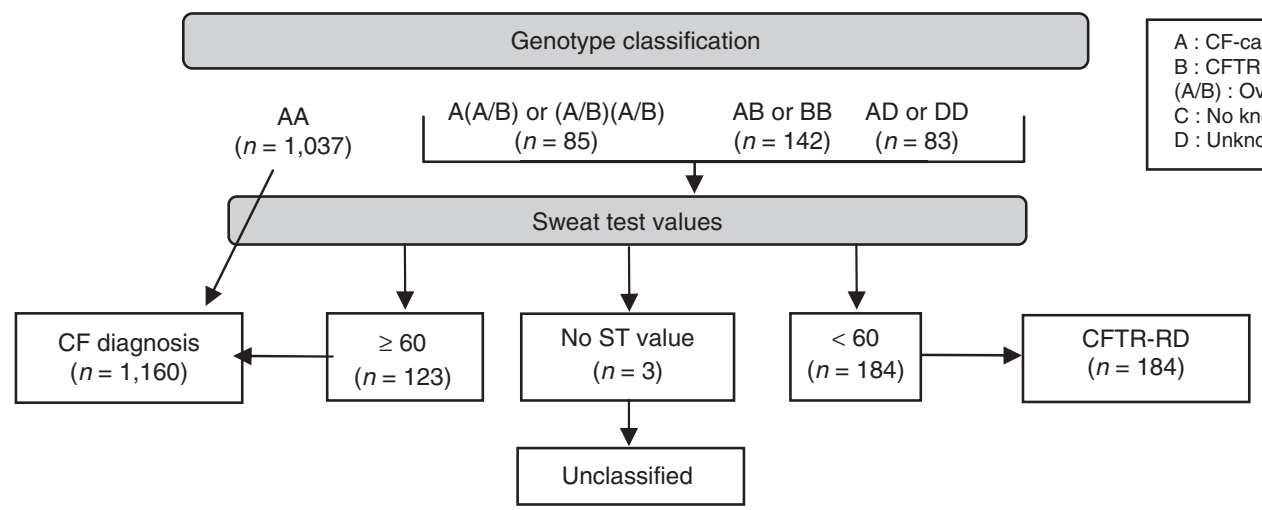

Figure 1 French cystic fibrosis (CF) newborn screening (NBS) algorithm. (a) Organizational algorithm. Comprehensive CFTR gene analysis is not part of the screening algorithm; it is only performed as a second-line diagnostic test for infants with one or no mutation detected by the CF30 kit (*) in whom CF or CFTR-RD was already diagnosed by sweat test (ST) and clinical assessment. (b) Diagnostic algorithm. Neonates carrying a homozygous AA genotype, a compound heterozygous genotype for $A$ and $A / B$ mutations and having a positive sweat test result were classified as having CF. The diagnostic conclusion of the $C F$ status for other neonates ( $A B, A C, A D, A-$-) was based on ST values. In cases of positive $S T$, the neonates were classified as having $C F$; if the $S T$ was negative or borderline, then the babies did not meet the CF diagnosis criteria and were classified with an equivocal CF diagnosis or as having CFTR-RD. When the results of ST were not available, the babies remained unclassified. Data shown in this figure concerning the number of newborns tested at day 3 , the number of newborns tested at day 21, and the number of CFTR 30 mutation analyses are the real numbers of tests performed by the 22 regional laboratories and the 9 genetic laboratories. The 65 children with false-negative results are divided into (i) 55 children with day 3 immunoreactive trypsin (IRT) levels under the cutoff, (ii) 3 children with day 3 IRT levels above the cutoff but notification failure, (iii) 5 children with day 3 IRT levels less than the day 21 recall cutoff value (i.e., day 3 IRT < 100), (iv) 1 child with a negative sweat test result, and (v) 1 child with day 21 IRT less than the cutoff. CF, cystic fibrosis; CFTR, cystic fibrosis transmembrane conductance regulator; CFTR-RD, CFTR-related disorder. 
Table 2 Summary of the numbers of newborns screened and cases detected, incidence, and sensitivity, specificity, and predictive values for the screening protocol, for the whole cohort and for the CF patients

\begin{tabular}{|c|c|c|}
\hline & CF & Alla \\
\hline Screened newborns & $5,947,148$ & $5,947,148$ \\
\hline Affected newborns & 1,263 & 1,450 \\
\hline Detected by NBS & 1,160 & 1,347 \\
\hline Missed by NBS & 65 & 65 \\
\hline $\mathrm{Ml}$ & 38 & 38 \\
\hline CFTR DNA 30-mutation analysis & 34,845 & 34,845 \\
\hline Incidence $(95 \% \mathrm{CI})$ & $2.12 / 10,000(2.00 / 10,000$ to $2.24 / 10,000)$ & $2.26 / 10,000(2.14 / 10,000$ to $2.38 / 10,000))$ \\
\hline Sensitivity (\%) $(95 \% \mathrm{Cl})$ & 95.10 (93.89 to 96.31$)$ & 95.40 (94.31 to 96.49$)$ \\
\hline $\begin{array}{l}\text { Sensitivity (\%) ( } 95 \% \mathrm{Cl}) \text { including MI with low } \\
\text { IRT levels as false negative }\end{array}$ & 92.45 (90.99 to 93.90$)$ & 92.90 (91.48 to 94.31$)$ \\
\hline Specificity (\%) (95\% CI) & 99.93 (99.92 to 99.93) & 99.93 (99.92 to 99.93) \\
\hline Positive predictive value (\%) (95\% Cl) & 22.26 (21.17 to 23.35$)$ & $24.19(23.07$ to 25.31$)$ \\
\hline Negative predictive value (\%) (95\% Cl) & 99.99 (99.98 to 99.99$)$ & 99.99 (99.98 to 99.99$)$ \\
\hline
\end{tabular}

CF, cystic fibrosis; CFTR, cystic fibrosis transmembrane conductance regulator; CFTR-RD, CFTR-related disorder; Cl, confidence interval; IRT, immunoreactive trypsin; MI, meconium ileus; NBS, newborn screening.

${ }^{a}$ CF, CFTR-RD, and unclassified cases.

$(n=5,0.43 \%)$ (see Supplementary Table S1 online). In addition 17 were homozygous for a rare mutation.

Those with false-negative results $(n=65)$ and cases of MI with low IRT levels $(n=38)$ over the study period were monitored by the questionnaires sent annually to the CF centers (representing 103 children).

Fifty-five of the 65 children with false-negative results had IRT levels at day 3 less than the cutoff level, with a median value of $47 \mathrm{ng} / \mathrm{ml}$ (range, 7-64). In six other cases, the children had no mutations detected by the CF30 kit; five of them had IRT levels at day 3 less than the day 21 recall cutoff (median, $88 \mathrm{ng} / \mathrm{ml}$; range, 79-98), whereas the sixth had an IRT at day 21 less than the recall cutoff. There were problems with the notification procedure for the remaining four patients.

Interestingly, cases of MI with low IRT levels $(n=38)$ represent only $20 \%$ of the total cases of MI $(n=196)$, with median IRT values of 51 and $113 \mathrm{ng} / \mathrm{ml}$ for the low and the high IRT group, respectively. Median IRT levels for the infants with MI did not differ from those of the other cases of CF (124 vs. $132 \mathrm{ng} / \mathrm{ml} ; P=0.31$ ).

Thus, taking infants who met classic $\mathrm{CF}$ diagnosis criteria together with both those with false-negative results diagnosed by symptoms and those with MI with IRT levels below cutoff, the incidence of classic CF was 2.12 per 10,000 live births (i.e., 1 in 4,708 ; $95 \%$ CI, $2.00 / 10,000$ to $2.24 / 10,000$ ). As previously described, ${ }^{11}$ we observed a wide range of regional variations ranging from 1 in 3,584 in Lorraine to 1 in 7,309 in Ile de France (Figure 2).

\section{Detection rate of the CF30 kit mutation panel and evaluation of allelic heterogeneity in France}

The present cohort of more than 1,000 screened neonates with CF presents a unique opportunity to reassess allelic heterogeneity in France and to compare findings with published data.
Table 1 summarizes the frequencies of the mutations identified by the kit in 2,320 alleles. p.Phe508del was present in $1,560(67.24 \%)$ alleles, varying from $50 \%$ in Central and Southern France (Regions Auvergne, Franche-Comté, and Provence-Alpes-Côte d'Azur) to $76 \%$ in Northern France (Regions Nord-Pas de Calais and Champagne-Ardennes). The variations in p.Phe508del frequency did not correlate with those observed in incidence $\left(r^{2}=0.036\right)$. Six other mutations had a relative frequency $\geq 1 \%$, accounting for a cumulative rate of $10.51 \%$. Another group of 11 mutations had respective frequencies ranging from 0.99 to $0.40 \%$. Moreover, 12 mutations ranging from 0.10 to $0.39 \%$ were observed in three to nine alleles.

The CF30 kit identified $87.67 \%$ of the $2,320 \mathrm{CF}$ alleles (i.e., 2,034) for a detection rate of $\geq 80 \%$ for all 22 French regions. Two regions with slightly lower detection rates were located in Central and Southern France, i.e., Franche Comté at $78.57 \%$ and Provence-Alpes-Côte d'Azur at $76.67 \%$ (data not shown).

The mutation spectrum in neonates with CF diagnosed through NBS is consistent with the previously reported spectrum in patients with CF diagnosed based on clinical symptoms. ${ }^{12}$ The percentage of the main mutations was similar (Figure 3); however, there were significantly higher rates of specific mutations, including p.Tyr122* (Y122X) in CF patients from the Réunion Island (prevalence, 0.97 vs. $0.16 \% ; P<10^{-6}$ ) and c. $2988+1 \mathrm{G}>\mathrm{A}(3120+1 \mathrm{G}>\mathrm{A})$ (prevalence, 0.82 vs. $0.09 \% ; P$ $<10^{-6}$ ) in patients of African origin.

Furthermore, large rearrangements were identified in 20 of the $2,320 \mathrm{CF}$ alleles ( 0.86 vs. $0.06 \%$ ), representing nearly $7 \%$ of the alleles not identified through the kit.

After comprehensive scanning, 198 other mutations were identified, with a nearly exhaustive representation of the mutated alleles $(99.7 \%)$, and only 7 alleles $(0.3 \%)$ remained unidentified. 


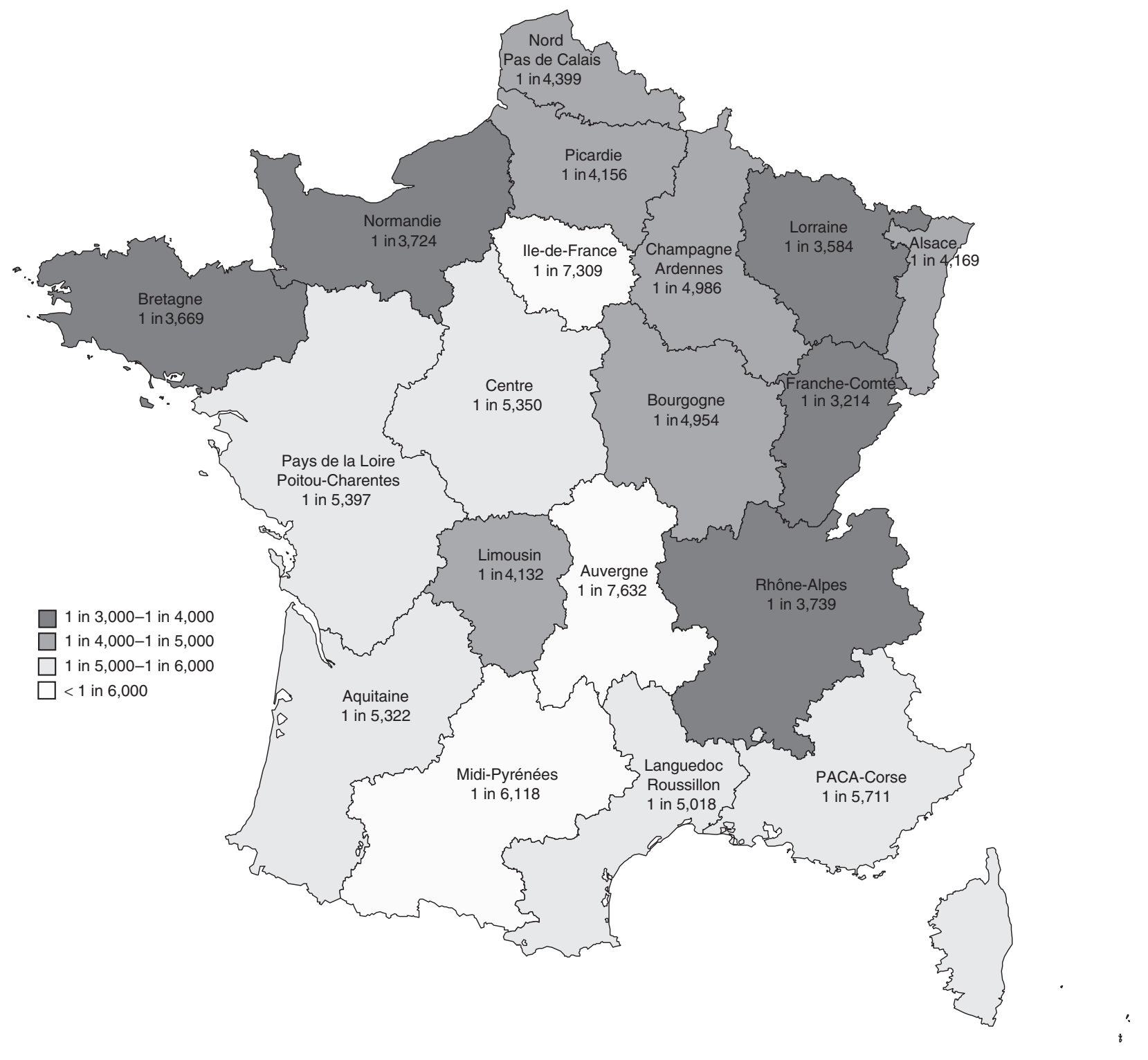

Figure 2 Regional differences in the incidence of cystic fibrosis during the studied period.

\section{DISCUSSION}

We report in this study the results of 8 years of the French CF NBS program based on an IRT/DNA protocol, followed by a comprehensive gene analysis in CF children.

Before the implementation of the French CF NBS program, expert groups compiled recommendations for screening strategy, including all technical aspects and the importance of close collaboration between laboratories and clinical CF centers to ensure efficiency. The study confirmed the performance of the CF30 panel and further comprehensive gene analysis, with detection rates of 87.67 and $99.7 \%$, respectively. To our knowledge, this is the highest mutation detection rate reported from a large heterogeneous nationwide population of screened newborns.

After combining genetic and ST results, 1,160 neonates were diagnosed with CF during the study period. A further 38 neonates with MI and IRT levels below cutoff were also considered to have $\mathrm{CF}$, and another cohort of 65 infants with symptoms suggestive of the disease, positive ST, and 2 CF-causing mutations undetected on the NBS program (false-negative results) were reported. Thus, overall, during this period, 1,263 infants were diagnosed with CF, giving a global incidence of 2.12 per 10,000 live births in France (i.e., 1 in 4,708; 95\% CI, 2.00/10,000 to 2.24/10,000), which was lower than the previously estimated incidence of $\mathrm{CF}$ in a Caucasian population (4.00/10,000 or 1 in 2,500).$^{27}$ According to these data, CF allele frequency is estimated at 0.014 , corresponding to an expected carrier frequency of 1 in 34 .

Further comprehensive gene analysis is sometimes routine, as in the California CF NBS algorithm, ${ }^{28}$ but in France it is implemented later in level 2 molecular biology laboratories for a limited number of neonates with positive or borderline STs. It identified 198 other mutations in $99.7 \%$ of the alleles, with 


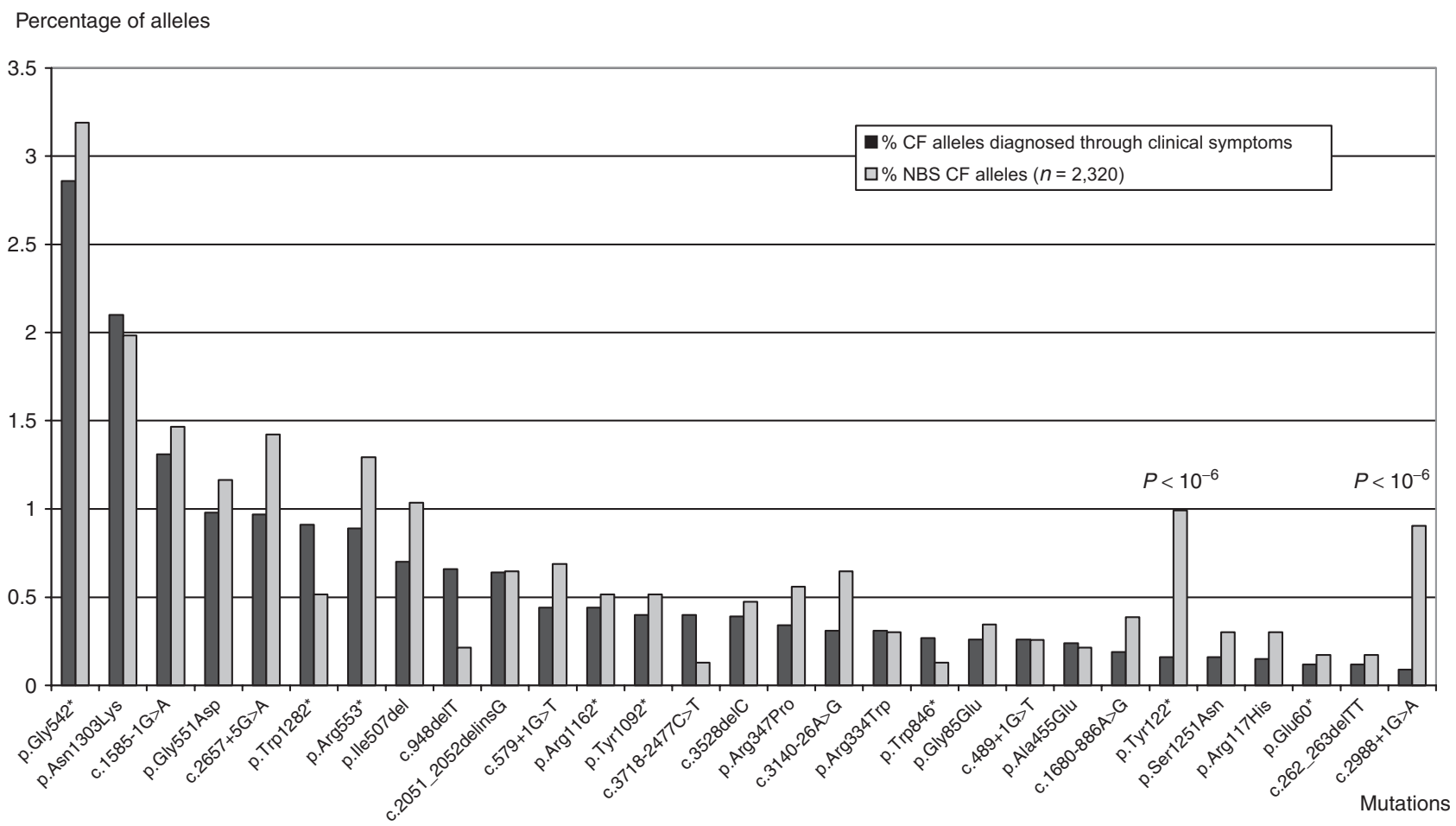

Figure 3 Comparison of the mutation spectrum in French cystic fibrosis (CF) patients for the mutations included in the CF30 kit, except for the p.Phe508del mutation. Dark gray, patients diagnosed based on clinical symptoms; light gray, patients identified based on newborn screening. Statistical analysis found a significant difference between patients diagnosed based on clinical symptoms and those based on newborn screening for the frequencies of the c.2988+1G>A and p.Tyr122* mutations. NBS, newborn screening.

only 7 unidentified alleles (including one case in which the parents refused complementary analysis), reflecting the allelic heterogeneity found in France and in other countries, such as the Czech Republic. ${ }^{29}$

Sensitivity and specificity were greater than $95 \%$ and $99 \%$, respectively, equivalent to the findings of the Australian study, ${ }^{30}$ which was the closest to the present study in terms of strategy and number of neonates screened. The present positive predictive value was better, possibly because of the panel of mutations analyzed.

The current nationwide French NBS algorithm for CF, which combines IRT assay/DNA analysis, fail-safe IRT, and STs, provided a good detection rate for infants with classic $\mathrm{CF}$, with only $5.6 \%$ false-negative results. We cannot be sure we have detected all the false-negative cases, but clinical symptoms of CF appear early in life and we think that after 3 years, the large majority of these cases have been diagnosed.

One point of concern, however, is that NBS identifies not only classic CF but also a small proportion of neonates with CFTRRDs, i.e., infants with borderline STs and one or two detected variations, and infants with STs $\leq 60 \mathrm{mmol} / \mathrm{l}$ with two detected mutations on $\mathrm{CF} 30$, who do not meet the criteria for the diagnosis of CF. Whether these cases, representing up to $13.66 \%$ of our overall cohort, half of which carry a p.Arg117His mutation, might benefit from NBS is highly questionable. Recently, Thauvin et al. ${ }^{31}$ assessed individuals carrying a p.Arg117His mutation and a CF-causing mutation, showing classic $\mathrm{CF}$ penetrance of $0.03 \%$ and severe CF penetrance in adulthood of $0.06 \%$. Considering that the aim of NBS is early diagnosis of classic forms of $\mathrm{CF}$, their findings provide a strong argument for removing the p.Arg117His mutation from the CFTR NBS mutation panel.

Clearly, genetic information concerning CFTR mutations is increasingly important, not only for more accurate genetic counseling of families but also for the development of new therapeutic approaches targeting specific mutations. Mutations can have different impacts on the CFTR protein, from the absence of synthesis to malfunction. Depending on their functional impact, new therapeutic approaches have emerged, with mutation-specific treatments that target specific gene defects. ${ }^{32}$ Potentially active agents have been identified and analyzed, resulting in several new compounds and, in one case (VX-770 for the p.Gly551Asp mutation), ${ }^{33}$ in a license in the United States and Europe. Treatments will clearly be mutation-based, and these data suggest that CFTR-targeted drugs might arrest disease progression and perhaps hamper the development of CF disease in infants diagnosed by NBS. Thus, the patient's genotype is the cornerstone of this approach, facilitating selection of patients to whom clinical trials can be offered.

\section{Conclusion}

In this study, we reported the results of a nationwide CF NBS program based on an IRT/DNA protocol, followed by a comprehensive CFTR gene analysis in children with CF. To our 
knowledge, the present detection rate is the highest reported from a large heterogeneous nationwide population of screened newborns.

Based on these results of the French 8-year experience with nearly 6 million newborns, we show that the 4 -tiered IRT/DNA/ IRT/ST CF-NBS procedure is an effective strategy for NBS for $\mathrm{CF}$ that could be easily implemented in other countries.

\section{SUPPLEMENTARY MATERIAL}

Supplementary material is linked to the online version of the paper at http://www.nature.com/gim

\section{ACKNOWLEDGMENTS}

In France, newborn screening for $\mathrm{CF}$ is supported financially by the Caisse Nationale d'Assurance Maladie des Travailleurs Salariés. The UMD database is sponsored by the French CF Association (Vaincre La Mucoviscidose). The authors thank the teams of the NBS laboratories: Guy Lalau and Adrien Pagin (CHRU Lille), Faiza Cabet and Yves Morel (CHU Lyon), Christine Clavel and Véronique Dalstein (CHU Reims), Jean Paul Bonnefont and Arnold Munnich (Hôpital Necker, Paris), Rémy Couderc and Laurence Jonard (Hôpital Trousseau, Paris), Dominique Laroche and Georges Travert (CHU Caen), and Eric Bieth and Véronique Gaston (CHU Toulouse), as well as the referring physicians of the specialized laboratories: Emmanuelle Girodon (Hôpital Henri Mondort, Créteil), Thierry Bienvenue (Hopital Cochin, Paris), Marie Claire Malinge (CHU Angers), Marie Pierre Reboul (CHU Bordeaux), and Alain Kitzis (CHRU Poitiers).

\section{DISCLOSURE}

The authors declare no conflict of interest.

\section{REFERENCES}

1. Cutting GR. Genetic heterogeneity and cystic fibrosis. Hum Mutat 2009;30:v.

2. Sims EJ, Clark A, McCormick J, Mehta G, Connett G, Mehta A; United Kingdom Cystic Fibrosis Database Steering Committee. Cystic fibrosis diagnosed after 2 months of age leads to worse outcomes and requires more therapy. Pediatrics 2007;119:19-28.

3. Accurso FJ, Sontag MK, Wagener JS. Complications associated with symptomatic diagnosis in infants with cystic fibrosis. J Pediatr 2005;147(suppl 3):S37-S41.

4. Lai HJ, Cheng Y, Farrell PM. The survival advantage of patients with cystic fibrosis diagnosed through neonatal screening: evidence from the United States Cystic Fibrosis Foundation registry data. J Pediatr 2005;147(suppl 3): S57-S63.

5. Balfour-Lynn IM. Newborn screening for cystic fibrosis: evidence for benefit. Arch Dis Child 2008:93:7-10.

6. Dijk FN, McKay K, Barzi F, Gaskin KJ, Fitzgerald DA. Improved survival in cystic fibrosis patients diagnosed by newborn screening compared to a historical cohort from the same centre. Arch Dis Child 2011;96:1118-1123.

7. Férec $C$, Verlingue $C$, Parent $P$, et al. Neonatal screening for cystic fibrosis: result of a pilot study using both immunoreactive trypsinogen and cystic fibrosis gene mutation analyses. Hum Genet 1995;96:542-548.

8. Scotet $\mathrm{V}$, de Braekeleer M, Roussey M, et al. Neonatal screening for cystic fibrosis in Brittany, France: assessment of 10 years' experience and impact on prenatal diagnosis. Lancet 2000;356:789-794.

9. Audrézet MP, Costes B, Ghanem N, et al. Screening for cystic fibrosis in dried blood spots of newborns. Mol Cell Probes 1993;7:497-502.

10. Farriaux JP, Vidailhet $M$, Briard ML, Belot V, Dhondt JL. Neonatal screening for cystic fibrosis: France rises to the challenge. J Inherit Metab Dis 2003;26:729744.
11. Munck A, Dhondt JL, Sahler C, Roussey M. Implementation of the French nationwide cystic fibrosis newborn screening program. J Pediatr 2008;153:22833, 233.e1.

12. Claustres M, Guittard C, Bozon D, et al. Spectrum of CFTR mutations in cystic fibrosis and in congenital absence of the vas deferens in France. Hum Mutat 2000;16:143-156.

13. De Boeck K, Wilschanski M, Castellani C, et al.; Diagnostic Working Group. Cystic fibrosis: terminology and diagnostic algorithms. Thorax 2006;61:627-635.

14. Southern KW, Munck A, Pollitt R, et al.; ECFS CF Neonatal Screening Working Group. A survey of newborn screening for cystic fibrosis in Europe. J Cyst Fibros 2007;6:57-65.

15. Farrell PM, Rosenstein BJ, White TB, et al.; Cystic Fibrosis Foundation. Guidelines for diagnosis of cystic fibrosis in newborns through older adults: Cystic Fibrosis Foundation consensus report. J Pediatr 2008;153:S4-S14.

16. Castellani C, Cuppens H, Macek M Jr, et al. Consensus on the use and interpretation of cystic fibrosis mutation analysis in clinical practice. J Cyst Fibros 2008;7:179-196.

17. Audrézet MP, Mercier B, Guillermit $H$, et al. Identification of 12 novel mutations in the CFTR gene. Hum Mol Genet 1993;2:51-54.

18. Le Maréchal $C$, Audrézet MP, Quéré I, Raguénès $\mathrm{O}$, Langonné $S$, Férec $C$. Complete and rapid scanning of the cystic fibrosis transmembrane conductance regulator (CFTR) gene by denaturing high-performance liquid chromatography (D-HPLC): major implications for genetic counselling. Hum Genet 2001;108:290-298.

19. Audrezet MP, Dabricot A, Le Marechal C, Ferec C. Validation of high-resolution DNA melting analysis for mutation scanning of the cystic fibrosis transmembrane conductance regulator (CFTR) gene. J Mol Diagn 2008;10:424-434.

20. Audrézet MP, Chen JM, Raguénès $O$, et al. Genomic rearrangements in the CFTR gene: extensive allelic heterogeneity and diverse mutational mechanisms. Hum Mutat 2004:23:343-357.

21. Sermet-Gaudelus I, Munck A, Rota M, Roussey M, Feldmann D, NguyenKhoa T; Groupe de travail "Dépistage néonatal" de la Fédération des centres de ressources et de compétences de la mucoviscidose. [French guidelines for sweat test practice and interpretation for cystic fibrosis neonatal screening]. Arch Pediatr 2010;17:1349-1358.

22. Dequeker E, Stuhrmann M, Morris MA, et al. Best practice guidelines for molecular genetic diagnosis of cystic fibrosis and CFTR-related disordersupdated European recommendations. Eur J Hum Genet 2009;17: $51-65$.

23. Ferec C, Cutting GR. Assessing the disease-liability of mutations in CFTR. Cold Spring Harb Perspect Med 2012;2:a009480.

24. Bareil C, Thèze C, Béroud C, et al. UMD-CFTR: a database dedicated to CF and CFTR-related disorders. Hum Mutat 2010;31:1011-1019.

25. Kiesewetter S, Macek M Jr, Davis C, et al. A mutation in CFTR produces different phenotypes depending on chromosomal background. Nat Genet 1993;5:274278.

26. Massie RJ, Poplawski N, Wilcken B, Goldblatt J, Byrnes C, Robertson C. Intron-8 polythymidine sequence in Australasian individuals with $\mathrm{CF}$ mutations $\mathrm{R} 117 \mathrm{H}$ and R117C. Eur Respir J 2001;17:1195-1200.

27. Welsh MJ, Accurso FJ, Cutting GR. Cystic fibrosis. In: Scriver CR, Sly WS, Valle D, Childs B, Vogelstein B, eds. The Metabolic and Molecular Basis of Inherited Disease. 8th edn. McGraw-Hill: New York, 2001:5121-5188.

28. Prach L, Koepke R, Kharrazi M, et al.; California Cystic Fibrosis Newborn Screening Consortium. Novel CFTR variants identified during the first 3 years of cystic fibrosis newborn screening in California. J Mol Diagn 2013;15:710-722.

29. Křenková P, Piskáčková T, Holubová A, et al. Distribution of CFTR mutations in the Czech population: positive impact of integrated clinical and laboratory expertise, detection of novel/de novo alleles and relevance for related/derived populations. J Cyst Fibros 2013;12:532-537.

30. Massie RJ, Curnow L, Glazner J, Armstrong DS, Francis I. Lessons learned from 20 years of newborn screening for cystic fibrosis. Med J Aust 2012;196:67-70.

31. Thauvin-Robinet $C$, Munck $A$, Huet $F$, et al.; Collaborating Working Group on $\mathrm{R} 117 \mathrm{H}$. The very low penetrance of cystic fibrosis for the R117H mutation: a reappraisal for genetic counselling and newborn screening. J Med Genet 2009;46:752-758.

32. Thursfield RM, Davies JC. Cystic fibrosis: therapies targeting specific gene defects. Paediatr Respir Rev 2012;13:215-219.

33. Ramsey BW, Davies J, McElvaney NG, et al.; VX08-770-102 Study Group. A CFTR potentiator in patients with cystic fibrosis and the G551D mutation. N Engl J Med 2011;365:1663-1672. 